\title{
Mechanisms of sex determination and transmission ratio distortion in Aedes aegypti
}

\author{
Kim Phuc Hoang ${ }^{1 *}$, Tze Min Teo², Thien Xuan $\mathrm{Ho}^{3}$ and Vinh Sy Le
}

\begin{abstract}
Background: More effective mosquito control strategies are urgently required due to the increasing prevalence of insecticide resistance. The sterile insect technique (SIT) and the release of insects carrying a dominant lethal allele (RIDL) are two proposed methods for environmentally-friendly, species-targeted population control. These methods may be more suitable for developing countries if producers reduce the cost of rearing insects. The cost of control programs could be reduced by producing all-male mosquito populations to circumvent the isolation of females before release without reducing male mating competitiveness caused by transgenes.
\end{abstract}

Results: An RNAi construct targeting the RNA recognition motif of the Aedes aegypti transformer-2 (tra-2) gene does not trigger female-to-male sex conversion as commonly observed among dipterous insects. Instead, homozygous insects show greater mortality among m-chromosome-bearing sperm and $\mathrm{mm}$ zygotes, yielding up to $100 \%$ males in the subsequent generations. The performance of transgenic males was not significantly different to wild-type males in narrow-cage competitive mating experiments.

Conclusion: Our data provide preliminary evidence that the knockdown of Ae. aegypti tra-2 gene expression causes segregation distortion acting at the level of gametic function, which is reinforced by sex-specific zygotic lethality.

This finding could promote the development of new synthetic sex distorter systems for the production of genetic sexing mosquito strains.

Keywords: Aedes aegypti, Sex determination, Transformer-2, Meiotic drive, Spermatogenesis, Culicinae

\section{Background}

The global economic burden of mosquito-borne diseases continues to grow due to the failure of current control measures. Two novel methods based on the suppression of reproduction have been applied in mosquitoes, namely the sterile insect technique (SIT) and the release of insects carrying a dominant lethal allele (RIDL) [1-5]. However, these methods produce offspring of both sexes and 0.5-1\% of mosquitoes are physically misidentified as males during the sexing step in these techniques. In mosquitoes, it is an essential prerequisite to release only males because the females are blood feeders and disease vectors [6]. Genetic sexing strains based on the RIDL system have been developed to produce flightless females [7] but the trait also

\footnotetext{
* Correspondence: kimhpoxford@gmail.com

'University of Engineering and Technology, Vietnam National University,

Hanoi, 144 Xuan Thuy, Cau Giay 10000Hanoi, Vietnam

Full list of author information is available at the end of the article
}

affects males, reducing their time in flight by $21 \%$ compared to wild-type mosquitoes [8]. These drawbacks have led to research focusing on the exploitation of sex and sexratio determination mechanisms to control mosquito populations.

A recent publication [9] has shown that a new autosomal sex-determining allele, which may or may not exhibit all the other characteristics of a sex chromosome, succeeds when linked to a sex-specific meiotic driver $(M D)$. The new sex-determining allele benefits from confining the driving allele to the sex in which it gains the benefit of drive. Aedes aegypti carrying a distorter gene $D$ shows meiotic drive when associated with the male-determining $M$ gene on the M-chromosome (chromosome I). Although the molecular basis of the $M D$ system is unclear, it causes a highly malebiased sex ratio phenotype in Ae. aegypti and all $M D$ males are genetic males. The excess of $M D$ males involves isochromatid breakage in the $\mathrm{m}$-chromosome before or 
during the diplotene phase of the first meiotic division, although some $\mathrm{m}$-sperm dysfunctions manifest later in spermatogenesis after the segregation of homologous chromosomes [10-13]. Intriguingly, $m D$ was not resistant to $M D$ as proposed, and the $M D-T 1$ enhancer was identified as a translocation from chromosome III [10], indicating that genetic dominance is not responsible for $M D$ in $A e$. aegypti. The molecular basis of $M D$ and transmission ratio distortion in Drosophila simulans has recently been shown to depend on endogenous retrotransposon-dependent RNA interference (RNAi) $[14,15]$. In a recent publication, the ectopic expression of an M-locus (Nix gene) in Ae. aegypti female embryos caused the initial development of male genitals and testes in more than $69 \%(16 / 23)$ of genetic females [16]. Nix knockout with CRISPR/Cas9 generated largely feminized genetic males. The authors concluded that Nix is the male-determining $M$ gene of $A e$. aegypti which is both required and sufficient to initiate male development. The results indicated that more genes may be required to complete male development, and this may complicate any transgenic strategy by affecting the fitness of transgenic insects. The detailed description of feminized antennae in $n i x^{-}$males and the failure of these feminized males to obtain a blood-meal indicated that the $M$ gene does not affect the development of a male proboscis. However, the mandibles and maxillae of the biting fascicle in the $n i x^{+}$females were not described. Female-tomale sex conversion mosquitoes are not harmless if the biting fascicle is still present and biting insects would therefore be unsuitable for a control program.

The D. melanogaster transformer-2 (tra-2) gene plays essential roles in both sex determination in the female soma and spermatogenesis in the male germ cells. The tra-2 gene encodes a non-sex-specific auxiliary splicing factor that promotes female sexual differentiation in insects by interacting with the female-specific product of the transformer (tra) gene [17-20]. The TRA/TRA-2 protein complex then regulates other genes that control sexual differentiation, including doublesex $(d s x)[21,22]$. In D. melanogaster, tra-2 is also involved in the specification of the male germ line, and a null tra-2 allele causes male sterility although the underlying mechanism is unclear [23-26]. The secondary structure of the TRA-2 protein comprises anarginine/serine-rich (RS) domain, an 81-residue RNA recognition motif (RRM), a 19-residue linker region unique to TRA-2 proteins, and a second C-terminal RS domain. The RRM and linker region are the most conserved components of TRA- 2 proteins among dipteran and non-dipteran insects $[27,28]$. The injection of Drosophila, Ceratitis and Anastrepha spp. embryos with synthetic tra-2 dsRNA causes the degradation of tra-2 mRNA and the conversion of females into pseudomales [17-21]. The Ae.aegypti genome contains four putative tra-2 homologs, namely AAEL009224, AAEL006416, AAEL009222 and AAEL004293 [27, 29] [VectorBase:
AAEL009224, AAEL006416, AAEL009222, AAEL004293]. The direct injection of synthetic dsRNAs representing three of these genes into Ae. aegypti embryos did not affect $d s x$ splicing during the larval stages, and did not produce intersex adult phenotypes [27].

Six transgenic Ae. aegypti Rock lines were therefore produced expressing the tra-2 RNAi construct Zoo-2 [30], which targets the tra-2 RRM (AAEL004293RRM) responsible for protein-protein interactions and the splicing of $d s x$ mRNA. The RNAi construct was driven by the tet operator (tet $\mathrm{O})$ from the tet transactivator system ( $t \mathrm{TA})$, which is generally active but can be suppressed in crosses with $t$ TA transgenic mosquitoes when tetracycline analogs are also supplied (Additional file 1: Figure S1) [31, 32]. The tra-2 RNAi construct also features a DsRed-2 marker gene linked to the RNAi sequence, which allows transgenic and wild-type flies to be distinguished in genetic crosses. Teo [30] tested the interaction between the Tet-responsive control element in line 6 and the Tetoff transactivator protein from another transgenic line. Homozygous tra-2 RNAi females (line 6) were thus crossed with homozygous LA513 males (Additional file 2: Table S1) [33] carrying the $t$ TA transactivator gene, but homozygous females + Tet yielded progeny with a 1:1 sex ratio and normal hatching and survival rates, whereas homozygous females - Tet yielded progeny showed a significant bias towards male without intersex adult phenotypes, indicating that the abnormal sex ratio should be attributed to the $t$ TA protein of LA513 fathers. The LA513 construct was also designed to kill the carrier's offspring from the third larval stage, hence also reducing the survival in the absence of Tet. Quantitative real-time PCR was used to measure the level of tra-2 mRNA remaining after knockdown in homozygous line 6 and wild-type Rock males, showing that the tra-2 expression level was reduced by an average $48.7 \%$ in line 6 relative to wildtype insects (Standard deviation $=4.98$ ) (Additional file 3: Figure S2) [30]. Based on evidence from other dipterous species, Teo considered the possibility of female-to-male sex conversion, but this would imply that up to $50 \%$ of the male progeny carry $\mathrm{mm}$ chromosomes and solid evidence based on karyotyping, sex-diagnostic PCR or crossing analysis were not shown [30].

To investigate the bias towards male progeny and the molecular basis of Ae. Aegypti sex determination by tra-2, we carried out a phylogenetic analysis of the RRM regions of putative TRA-2 homologs in Culicinae mosquitoes followed by a more detailed genetic analysis of line 6 [30]. We tested the mating capacity of transgenic males in competition experiments. We also injected synthetic tra-2 RNAi constructs into Ae. aegypti embryos to observe their 
effect during transient expression. Here we report a potentially novel mosquito sex-determination mechanism in which the tra-2 gene is responsible for segregation distortion $(S D)$ and female lethality in the subsequent generation of mosquitoes.

\section{Methods}

\section{Phylogenetic analysis}

The RRM amino acid sequences described herein are $D$. melanogastertra-2 isoform C, E [GenBank:NP 476766.1], M. domesticatra-2 [GenBank:XP 005185276.1], An. gambiaetra-2 [VectorBase:AGAP006798] andCx. quin quesfasciatustra-2 [VectorBase:CPIJ016646]. Three further Ae. aegyptitra-2 RRMs (AAAEL009222, AA AEL006416 and AAAEL009224 [VectorBase]) were also analyzed, as well as Ae. aegypti, Ae. albopictus and Ae. polynesiensis RRM1 [GenBank: KJ147318, KJ147321, KJ147316 and KJ147314] and RRM2 [GenBank: KJ147317, KJ147320 and KJ147315]. RRM1 is the RRM domain of AAEL004293. The evolutionary history was inferred using the maximum likelihood method based on the JTT matrix model. The bootstrap consensus tree inferred from 1000 replicates was taken to represent the evolutionary history of the taxa. Branches corresponding to partitions reproduced in less than $50 \%$ of the bootstrap replicates were collapsed. The percentage of replicate trees in which the associated taxa clustered together in the bootstrap test (1000 replicates) is shown next to the branches. Initial trees for the heuristic search were created by applying the neighborjoining method to a matrix of pairwise distances estimated using a JTT model. Nine amino acid sequences were analyzed. Positions containing gaps and missing data were eliminated. The final dataset contained 78 positions. Evolutionary analysis was carried out using MEGA5 [34, 35].

\section{Plasmid construction}

The Zoo-2 construct and line 6 were prepared as previously described [30]. Briefly, the Ae. aegypti AAEL004293 sequence, which shows the greatest similarity to $D$. melanogastertra-2, was screened to find the RRM (predicted by PROSITE), and a 135-bp sequence was used to create the RNAi construct. This was assembled using a PiggyBac backbone from the LA513 plasmid [33] fused to a PCR fragment containing a tet operator sequence and minimal promoter (tetO7-CMV) and two Ae. aegypti tra2 inverted repeats connected by an intron. The LA513 construct was digested with SrfI and AscI to remove the $t \mathrm{TA} /$ tet $\mathrm{O} 7$ transactivator cassette and the backbone was trimmed to blunt ends before re-ligation with T4 DNA polymerase.

A 1770-bp DNA fragment containing (1) $376 \mathrm{bp}$ of the tetO7-CMV cassette [1409-1784, GenBank:KC710231.1]; (2) 285 bp of the D. melanogaster NIPP1 gene [512-793, GenBank:AJ427611.1]; and (3) 922 bp of the rabbit $\beta$ - globulin 3' untranslated region [14515-15435, GenBan$\mathrm{k}: \mathrm{AB} 236435.1]$ was amplified from an available DNA template using the primers NotIF (5'-CGA TCA GCG GCC GCA AAG CTG GGA GCA ATT CTC GCA-3') and NaeIR (5'-GCA GTC GCC GGC GCT ATG GGC ATA TGT TGC CA-3'). The sequences were amplified by PCR in a $25-\mu \mathrm{l}$ reaction comprising $2.5 \mu \mathrm{l}$ PCR buffer, $1.5 \mu \mathrm{l} 25 \mathrm{mM} \mathrm{MgCl} 2,0.5 \mu \mathrm{l}$ each dNTP $(10 \mathrm{mM})$ and $0.5 \mu \mathrm{l}$ of each primer $(10 \mathrm{pmol} / \mu \mathrm{l})$. This was supplemented with $0.15 \mu \mathrm{l} \mathrm{Taq}$ DNA polymerase $(5 \mathrm{U} / \mu \mathrm{l})$ and $10-40 \mathrm{ng}$ of template DNA. After heating to $94{ }^{\circ} \mathrm{C}$ for 4 min, we carried out 35 cycles of denaturation at $94{ }^{\circ} \mathrm{C}$ for $30 \mathrm{~s}$, annealing at $54{ }^{\circ} \mathrm{C}$ for $90 \mathrm{~s}$ and extension at $72{ }^{\circ} \mathrm{C}$ for $150 \mathrm{~s}$ before holding at $72{ }^{\circ} \mathrm{C}$ for $10 \mathrm{~min}$. The re-ligated $L A 513$ was mixed with the PCR fragment at a 3:1 molar ratio and digested with NotI and NaeI. The resulting plasmid was cloned in competent cells then isolated and digested with SacII and BamHI to remove the NIPP1 gene, leaving the tetO7-CMV minimal promoter cassette and rabbit $\beta$-globulin 3'-UTR available for the tra-2 RNAi core sequence. The tra-2 sequence was amplified using four different primers in three different combinations. All primer sequences used to amplify the RRM sequence and the tra-2 intron fragment are listed in Additional file 2: Table S8. Primers 1, 2, 3 and 4 were flanked by SacII, XhoI, BamHI and EcoRI sites, respectively.

The inverted repeats of the Zoo-2 construct were connected by a 245-bp tra-2 intron fragment (12204241220669 in supercont1.113). The PCR products amplified by primer pairs $1 / 2$ and $3 / 4$ were digested with XhoI and EcoRI and then ligated to the tra-2 intron fragment, which was amplified using primers 5 and 6 . The RNAi core structures were then digested with SacII and BamHI and mixed with the linear plasmid described above in a 1:3 molar ratio. The size of the final plasmid was $11,448 \mathrm{bp}$.

\section{Mosquito transformation and analysis}

Ae. aegypti Rock mosquitoes (Ae. aegypti Rockefeller line, Liverpool School of Tropical Medicine) and transgenic line 6 were reared using a standard protocol [36]. The posterior poles of 2500 Rock embryos were microinjected with a cocktail of the Zoo-2 and transposase constructs (0.6 and $0.3 \mu \mathrm{g} / \mu \mathrm{l}$, respectively) using a Femtotip II with the NiKon Eclipse TS100 microinjector system. The transposase construct was a helper plasmid carrying the D. melanogaster heat shock 70 (hsp70) promoter driving the expression of the PiggyBac transposase. Six transformed lines were established, distinguished by remarkable differences in DsRed-2 marker gene expression in G1 larvae, and we used line 6 [30] for the further experiments described herein.

Inverse PCR was used to identify genomic sequences adjacent to the insertion site of the tra-2 RNAi construct as previously described [37]. The PiggyBac 5' sequence 
was used to design two pairs of nested primers which amplify the same insertion and flanking regions but generate products differing in size by 214 bp (Taq $\mathrm{I}$-PB5-1, 5'-GAT GAG GTA CAT GAA GTG CAG CCA-3' and TaqoI-PB5-2, 5'-CAT GCG TCA TTT TGA CTC ACG C-3'; Taq $\alpha$ I-PB5-3, 5' -TAG CCG AGT CTC TGC ACT GAA C-3' and Taq ${ }^{\prime}$ I-PB5-4, 5'-CAG TGA CAC TTA CCG CAT TGA C-3'). The sequences were amplified by PCR in a $25-\mu \mathrm{l}$ reaction with the same ingredients listed above except we used 10-20 ng of template DNA. After heating to $94{ }^{\circ} \mathrm{C}$ for $4 \mathrm{~min}$, we carried out 35 cycles of denaturation at $94{ }^{\circ} \mathrm{C}$ for $45 \mathrm{~s}$, annealing at $55{ }^{\circ} \mathrm{C}$ for $60 \mathrm{~s}$ and extension at $72{ }^{\circ} \mathrm{C}$ for $60 \mathrm{~s}$ before holding at $72{ }^{\circ} \mathrm{C}$ for $10 \mathrm{~min}$. The first primer pair (TaqoI-PB5-1 and TaqaI-PB5-2) yielded a 981-bp product whereas the

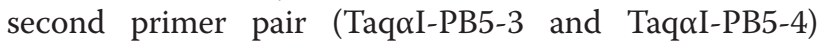
yielded a 767-bp product. The nested primer binding sites allowed us to verify that the amplification was reproducible and also confirmed the single insertion site. If there was more than one insertion, each PCR should produce more than one product after 35 cycles due to the presence of identical primer binding sites at each locus.

The flanking regions were sequenced and two diagnostic primers were designed to test the allelic status of the insertion (Flk-2, 5'-GCA GAA GCT TGA ATT GAA GCC TCT GA-3', and PB5-2, 5'-GCA GAG AGG ATA TGC TCA TCG TCT-3'). Wild-type insects yielded a 275-bp product whereas heterozygotes yielded this plus an additional 584-bp product containing the insert. Mass crossing between heterozygous males and females allowed the selection of second-instar larvae and pupae in the next generation showing the brightest DsRed fluorescence, corresponding to homozygous insertions. This was confirmed by diagnostic PCR once the individuals had reached reproductive age. Eggs from homozygous parents were pooled to establish the homozygous line. Larvae and pupae with a DsRed-2 marker were screened using an Olympus SZX9 fluorescence stereo microscope. After separating male and female pupae, the number of individuals expressing the DsRed-2 marker was counted in each group.

To prepare mosquitoes for genetic crosses, each halfgravid female from the homozygous line was separately collected in a Drosophila vial containing a wet filter paper disk and allowed to lay eggs in dark. Each egg batch was hatched in deoxygenated water and grown separately. When the progeny developed to the pupal stage, isofemale siblings were placed into two cages $(20 \mathrm{~cm} \times 20 \mathrm{~cm})$ for males and females, every day until the last pupae eclosed, and the sex ratio was immediately counted. This process usually took $4-6$ days at 27 $\pm 2{ }^{\circ} \mathrm{C}$, depending on the size of each family. Mosquitoes were fed with $20 \%$ sugar or honey solution and were kept for 3 additional days to ensure that the last eclosed insect was 3 days old. The transgenic mosquitoes used in the crosses varied from 3 to 9 days old. This procedure was used for mosquitoes in the experiments in Fig. 2 (a, b and c) and Fig. 3.

\section{Quantitative RT-PCR (qPCR)}

The expression of tra-2 in transgenic males and wildtype Rock males was measured by qPCR [30]. Briefly, male pupae were collected in pools of five male pupae in three replicates for RNA extraction. Template cDNA was obtained from one $\mu \mathrm{g}$ DNase treated RNA of each sample, using SuperScript VILO cDNA Synthesis Kit (Invitrogen) for transcription and then performed using 1 to 20 dilutions of the cDNAs using SYBR Green I for qPCR. Three qPCR assays were carried out to ensure the results were consistent and an average expression level was calculated. After heating to $95 \mathrm{C}$ for $15 \mathrm{~min}$, we carried out 45 cycles of denaturation for $10 \mathrm{~s}$ at $95{ }^{\circ} \mathrm{C}$, annealing for $10 \mathrm{~s}$ and extension for $20 \mathrm{~s}$ at $72{ }^{\circ} \mathrm{C}$. The annealing temperature was primer-specific, i.e. $54{ }^{\circ} \mathrm{C}$ for the tra-2 gene (F 5'-GAA ACA TCG GCC TGT TCA TC-3' and R 5'-GCT GGT TTC GTT GGT GTA GC$3^{\prime}$ ), and $59^{\circ} \mathrm{C}$ for the housekeeping gene Actin5C (F $5^{\prime}$ ATC GTA CGA ACT TCC CGA TG-3' and R 5'-ACA GAT CCT TTC GGA TGT CG-3'). The tra-2 primers generated a 120-bp product from tra-2 exon 155 bp upstream of the RNAi target site, whereas the Actin5C primers generated a 125-bp fragment. Readings were taken every $1{ }^{\circ} \mathrm{C}$ with a 1 -s hold for the melting curve between $50{ }^{\circ} \mathrm{C}$ and $95{ }^{\circ} \mathrm{C}$. The relative standard curve method was used to calculate expression levels (ABI Prism 7700 Manual, Applied Biosystems) with Actin5C as an endogenous reference and the wild-type Rock mRNA as an exogenous calibrator.

\section{RRM sequences from other Culicinae mosquitoes and} microinjection of Ae. aegypti with the tra-2 RNAi construct Ae. albopictus mosquitoes were collected from Northern Vietnam, Central Laos (Khamcot) and Malaysia (Kuala Lumpur). Larval morphology was confirmed and DNA was extracted from five individuals from each site using the Qiagen DNA extraction kit, for RRM amplification and sequencing. Seven dried Ae, polynesiensis specimens were obtained from Fiji and two from Tahiti. The morphology of these samples was confirmed and DNA extracted and tested as above. RRM regions from Ae. albopictus and Ae. polynesiensis were amplified by PCR using primers CLF (5'-AGT AAG TGC CTC GGT GTG TTC GGC CT-3') and CLR (5'-CCG GTC ACC GAA TAA TCC ACT CAA$\left.3^{\prime}\right)$ spanning a 26-bp proximal segment and a 23-bp distal segment of the Ae. aegypti supercontig 1.113 (12211821220943). The sequences were amplified by PCR in a $25-\mu \mathrm{l}$ reaction comprising $2.5 \mu \mathrm{l}$ PCR buffer, $1.5 \mu \mathrm{l} 25 \mathrm{mM}$ $\mathrm{MgCl}_{2}, 0.5 \mu \mathrm{l}$ each $\mathrm{dNTP}(10 \mathrm{mM})$ and $0.5 \mu \mathrm{l}$ of each 
primer $(10 \mathrm{pmol} / \mu \mathrm{l})$ supplemented with $0.15 \mu \mathrm{l}$ Taq DNA polymerase (5 U/ $\mu \mathrm{l})$ and $10-40 \mathrm{ng}$ of template DNA. After heating to $94{ }^{\circ} \mathrm{C}$ for $4 \mathrm{~min}$, we carried out three amplification cycles at $94{ }^{\circ} \mathrm{C}$ for $30 \mathrm{~s}, 59{ }^{\circ} \mathrm{C}$ for $30 \mathrm{~s}$ and $72{ }^{\circ} \mathrm{C}$ for $45 \mathrm{~s}$, three cycles at $94{ }^{\circ} \mathrm{C}$ for $30 \mathrm{~s}, 57{ }^{\circ} \mathrm{C}$ for $30 \mathrm{~s}$ and $72{ }^{\circ} \mathrm{C}$ for $45 \mathrm{~s}$, and 35 cycles at $94{ }^{\circ} \mathrm{C}$ for $30 \mathrm{~s}, 54{ }^{\circ} \mathrm{C}$ for $30 \mathrm{~s}$ and $72{ }^{\circ} \mathrm{C}$ for $45 \mathrm{~s}$, before holding at $72{ }^{\circ} \mathrm{C}$ for $10 \mathrm{~min}$. The 240 bp product among multiple bands was purified from agarose gels using the Qiagen extraction kit. Strong bands were sequenced immediately whereas weaker bands were reamplified before sequencing by diluting $1 \mu \mathrm{l}$ of the product $10-100$-fold and using $1 \mu \mathrm{l}$ of the dilution as the template in another round of PCR as described above. The DNA sequences were translated in silico using DNAsp v5.10.01 confirming the presence of the complete RRM amino acid sequence from -2 to +78 (predicted by PROSITE). Five $A e$. albopictus samples from Northern Vietnam had identical RRM2 sequences [GenBank:KJ147319]. Among the Ae. albopictus samples from Central Laos (Khamcot), four samples had identical RRM2 sequences [GenBank:KJ147320], and one had an RRM1 sequence [GenBank:KJ147321]. Among the Ae. albopictus samples from Malaysia (Kuala Lumpur), three samples had identical RRM2 sequences [GenBank:KJ147317], one had an RRM1 sequence [GenBank:KJ147318.1] and one was heterozygous for RRM1 and RRM2. Two Ae. polynesiensis samples were obtained from Tahiti, but only one produced enough DNA for PCR and this carried the RRM1 sequence [GenBank:KJ147314]. Among the five Ae. polynesiensis samples from Fiji, three had identical RRM1 sequences [GenBank:KJ147316], one had an RRM2 sequence [GenBank:KJ147315] and one was heterozygous for RRM1 and RRM2.

Embryos from Ae. aegypti Rock mosquitoes were collected and a Femtotip II and FemtoJet microinjector system was used to inject the posterior of each embryo with the tra-2 RNAi plasmid construct $(1.6 \mu \mathrm{g} / \mu \mathrm{l})$ to avoid the anticipated rapid in vivo degradation of dsRNA. Larvae were examined under a fluorescence stereomicroscope as above.

\section{Tests for reduced fertility and the analysis of} spermatozoa in transgenic and natural meiotic drive $(M D)$ mosquitoes

Two homozygous lines (2 and 10) were re-established from the heterozygous progeny of ${ }^{\top} \mathrm{M} 2$ and ${ }^{\top} \mathrm{M} 10$. Offspring from the intercrosses between heterozygotes were individually checked by PCR after mating and laying eggs. If both mother and father were homozygous, their eggs were used to establish the homozygous line. Males eclosed on the same day were kept in the same 2000-ml paper cup to accurately control for their age. Groups of five 3-day-old and 15-day-old males were collected from lines 2 and 10 (isofamily lines from line 6) and Rock.
Each male was individually crossed with three virgin Rock females, i.e. 30 males and 90 females in total. From each set of three females, one was blood fed to lay eggs, one was dissected to examine the spermathecae immediately after coitus and the third one was dissected after 22 days.

Crosses were also set up between T37 males and drivesusceptible RED females. RED is a laboratory strain that carries multiple morphological mutant markers and was previously shown to be highly sensitive to meiotic drive. All three chromosomes of this strain contain genetic markers. T37 is a strain that carries a strong driver for meiotic drive. This strain originated from field samples collected from Trinidad [13]. F1 mosquitoes were intercrossed and sperm in the testes and spermathecae were tested. Images were captured using a DP50 digital camera connected to an Olympus BX51or ZEIZZ AXIOSKOP 2 microscope.

\section{Mosquito dissection and crossing experiments}

Testes and spermathecae were dissected in Drosophila Ringer's solution under a stereomicroscope. One testis or spermatheca was immersed in $12 \mu \mathrm{l}$ Ringer's solution on a slide and covered with a $24 \times 50 \mathrm{~mm}$ coverslip. A pencil was used to press on the coverslip to release sperms from the organ and to distribute them onto the slide surface. Sperm activities were observed under an Olympus BH-2 microscope. The slide was cooled to $-20{ }^{\circ} \mathrm{C}$ for $2 \mathrm{~min}$ to inactivate the sperm and was returned to the microscope stage for sperm counting under a grid eyepiece. In artificial mating experiments, females were mated in rapid succession [38] with transgenic and wild-type males to investigate the interaction between dysfunctional and healthy sperm within the same spermatheca. The first male was removed after $5-10 \mathrm{~s}$ of coitus to reserve space for a second male.

\section{Competitive mating experiments}

Competitive mating between transgenic and Rock males was initiated by resting both types of males together in cages before releasing females.

\section{TRA/TRA-2 and NvdsxRE motif searches}

We downloaded the expressed gene sequences of nine insects, namely Ae. aegypti, An. gambiae, Cx. quinquefasciatus, D.melanogaster, Bombyxmori, Apis mellifera, Nasonia vitripennis, Triboliumcastaneum and Ixodes scapularis from ftp://ftp.ncbi.nih.gov/repository/UniGene/. Data from seq.uniq.gz were used, although these include only one transcript from each gene and therefore may not contain all transcripts containing sex-specific splicing motifs. We also searched for these motifs in seq.all.gz which contains almost all the transcripts of each gene. However, all known transcripts remain to be updated in many important genes, 
e.g. $d s x$. We therefore decided to limit our results to the seq.uniq.gz search. Because each sex-specific splicing motif is usually distributed in a cluster of more than three units, we limited our search to genes containing a cluster of at least three patterns between 4 and $40 \mathrm{bp}$ apart. The minimum distance default helps to avoid the detection of microsatellites, whereas the maximum distance default is used to ensure the sequences are clustered. We searched for $N v d s x R E$ motifs [NGAAGAWN] in all nine species. We also searched for the TRA/TRA-2 motifs [39] found in $D$. melanogaster and An. gambiae, respectively [TC(T/A)(T/ A)CAATCAACA] and [UCgcCgAUCAACc, cCAUCguU CAACc, UCAACA-UCAuCg, UCUcCAAUCAAuc, aCAU CAAUCAAuA, aCAUCAAUCAAuc].

\section{Statistical analysis}

We used Python (http://www.compileonline.com/execute_python_online.php) for $\mathrm{X}^{2}$ analysis and created the corresponding charts using Microsoft Excel 2007.

\section{Results}

\section{Comparison of AAEL004293 RRM domains in the Aedes} lineage

RRM domains from Ae. polynesiensis and Ae. albopictus were amplified by PCR and characterized by sequencing, revealing the two haplotypes RRM1 and RRM2. These showed 100 and $88.46 \%$ amino acid similarity, respectively, to the AAEL004293 RRM domain of Ae. aegypti Rock. We also found RRM2 in two Ae. polynesiensis samples and RRM1 in three Ae albopictus samples. A reconstructed maximum likelihood tree [34, 35] showed that AAEL004293 RRM1 clustered with RRM2 and putative tra-2 genes from Anopheles gambiae and Culex quinquesfaciatus rather than paralogs in Ae. aegypti (Fig. 1, Additional file 4: Figure S3 and Additional file 2: Table S2). We concluded that AAEL004293 probably originated from a duplication of tra-2 in a common ancestor of mosquitoes following the separation of mosquitoes from the remaining diptera.

\section{Investigation of the genetic mechanism of sex- determination}

Transgenic line 6 was analyzed in genetic crossing experiments, which are summarized in Additional file 2: Table S3. In some crosses, the transgenic mosquitoes are described as DsRed-2 males or females to distinguish them from nontransgenic mosquitoes in the same brood.

The transgene flanking sequence in line 6 was analyzed by inverse PCR (see methods) [37]. Template genomic DNA from line 6 (digested with $\mathrm{Taq}^{\alpha} \mathrm{I}$ ) was amplified using two pairs of nested inverse PCR primers, yielding products of 981 and $767 \mathrm{bp}$, respectively, suggesting only one insertion jumped into the line 6 genome. Additional PCR products should have been present after 35 cycles of the

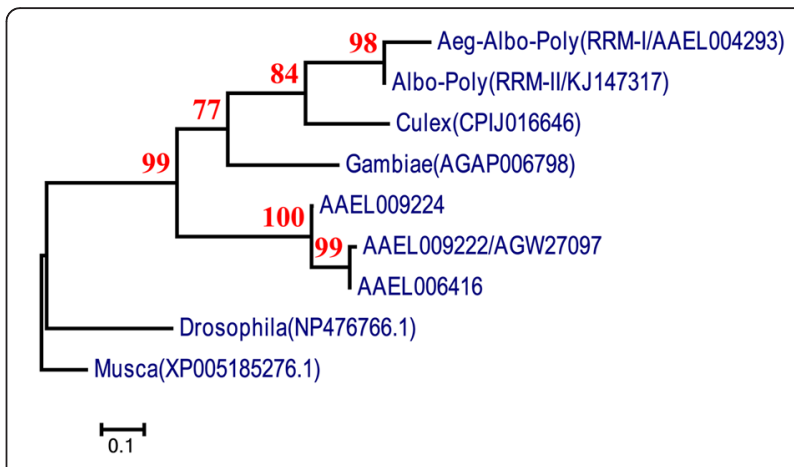

Fig. 1 Phylogenetic tree derived from a maximum-likelihood analysis of TRA-2 RRM domain protein sequences. The phylogeny suggests that the duplication of AAEL004293 probably occurred in a common ancestor of mosquitoes after the split of this ancestor from other diptera. The sequences of RRM domains were sourced from Ae. aegypti (Aeg); Ae. albopictus (Alb); Ae. polynesiensis (Poly); Cx. quinquesfaciatus (Culex); An. gambiae (Gambiae); Drosophila melanogaster and Musca domestica. AAAEL009222/AGW27097, AAAEL006416 and AAAEL009224 are the three other Ae. aegyptitra-2 homologs. The protein IDs for the RRM domains are shown on the branches of the phylogenetic tree. Bootstrap values are indicated in each node. The scale bar shows the branch length, representing the number of substitutions per site. Protein sequences in the phylogenetic tree can be found in the VectorBase and NCBI database with the following IDs: VVectorBase: AAAEL009222/AGW27097, AAAEL006416, AAAEL009224 CPIJ016646, AGAP006798], [GenBan: KJ147314, KJ147315, KJ147316, KJ147317, KJ147318, KJ147319, KJ147320, KJ147321, NP476766.1 and XP005185276.1]

amplification if there was more than one insertion. A diagnostic PCR was used to establish homozygous colonies.

Figure 2a shows male/female ratios in progenies of crosses between 10 pairs of homozygous parents ranging from 3 to 9 days in age (see methods). Interestingly, even in the absence of $t \mathrm{TA}$, three of 10 crosses yielded predominantly males, with $94 \%$ males in the most extreme case. The other seven crosses produced 1:1 sex ratios. Sex ratio distortion was not associated with a reduction in progeny size or hatching rate in any of the crosses. We therefore picked 10 random homozygous males (M1-10) and females (F1-10) from the progeny of the most male-biased crosses (Fig. 2a). These individuals were singly outcrossed with wild-type Rock females and males, respectively (Fig. 2b and c). Male ratios in the offspring produced by the M1-10 males showed a sex ratio bias similar to the previous generation, with five of the crosses producing $83-98 \%$ males and the other five also yielding excess males but not to the same extreme (Fig. 2a and b) (see Additional file 5).

Sex ratio distortion was inherited only through the male parent. The hatching rates were $>80 \%$ in all the crosses, indicating that the male excess was not caused by significant female embryonic lethality. No sex ratio distortion was observed in the progeny of crosses between homozygous females and wild-type Rock males 


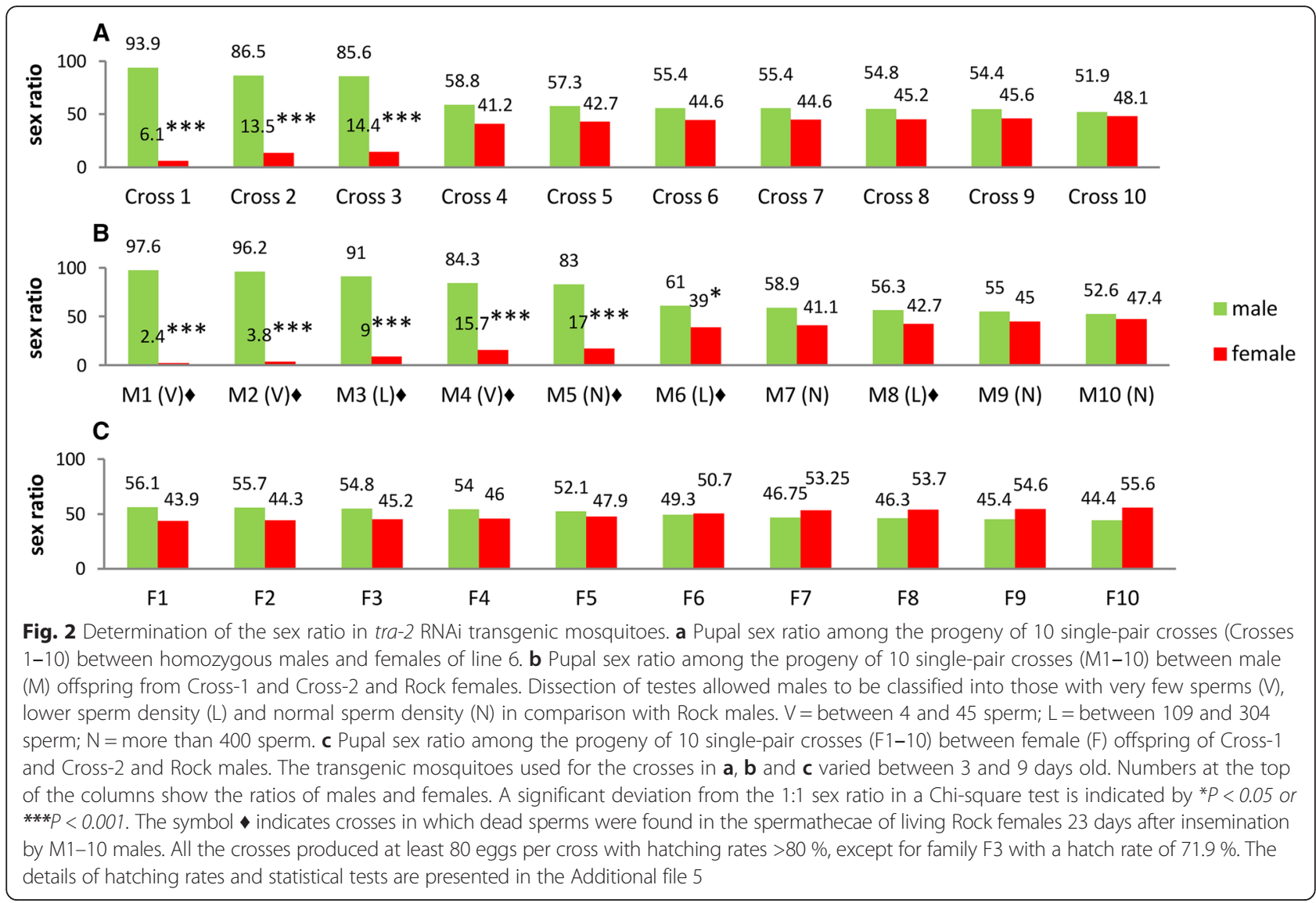

(Fig. 2c) suggesting the knockdown did not cause female-to-male sex conversion but that the distortion must be related to male gametogenesis.

The M1-10 parents were dissected to examine their spermatozoa. Three males produced only a few sperm, another three had a lower sperm count than normal and the remaining four had a sperm count similar to the Rock male controls. The Rock females crossed with the M1-10 males were blood fed for a second or third time to yield two further egg batches, and were dissected 2223 days after mating to examine the sperm present in the spermathecae. In seven of the 10 females, almost all the sperm were dead and tended to aggregate when released into Ringer's solution, and the few living sperm were motile (marked in Fig. 2b).

The between-family sex ratio variations shown in Fig. $2 \mathrm{a}$ and $\mathrm{b}$, and the excess male progeny resulting from sperm depletion were strongly reminiscent of the outcome when Ae aegypti males carrying the $D$ gene linked to male-determining factor $M$ were crossed with any female of a strain sensitive to the meiotic drive effect $(M D)$, whose sons subsequently produced male-biased progeny $[10,11]$. However, natural $M D$ males show no reduction in their fertility unless mated sequentially to more than 15 females [12]. Moreover, mass mortality of sperms in the spermathecae has never been reported in cases of meiotic drive, and our recent $M D$ tests for reduced fertility were negative (Additional file 2: Table S4) [13]. In the abovementioned test, offspring produced by crossing T37 males with RED females (see methods) were intercrossed in the F2 generation, and spermathecae dissected from females 22 days after intercrosses contained active sperms.

In the $M D$ systems, successive crosses to sensitive Rock females should produce male-biased progeny [10, 11, 40]. To test whether the heterozygous sons from homozygous fathers had been subjected to drive via the $M D$ system, we crossed 25 heterozygous males from the biased progenies of M1 and M2, and the unbiased progenies of M9 and M10, with 25 virgin wild-type Rock females (Fig. 2b). All the mass crosses showed a 1:1 sex ratio and a 1:1:1:1 segregation ratio for wild-type males, DsRed-2 males, wildtype females and DsRed-2 females $\left(P>0.05\right.$; all $X^{2} \leq 5.73$; $d f=3$ ) as shown in Fig. 3a (see Additional file 5).

There was no deviation from the anticipated 1:1 ratio when testing the overall or male (DsRed-2): wild-type ratio or the male (DsRed-2):female(DsRed-2) ratio, confirming again that there was a single transgene insertion, that none of the 25 males were chromosomal karyotype $\mathrm{mm}$, and that the jumping site in line 6 was an autosome. 


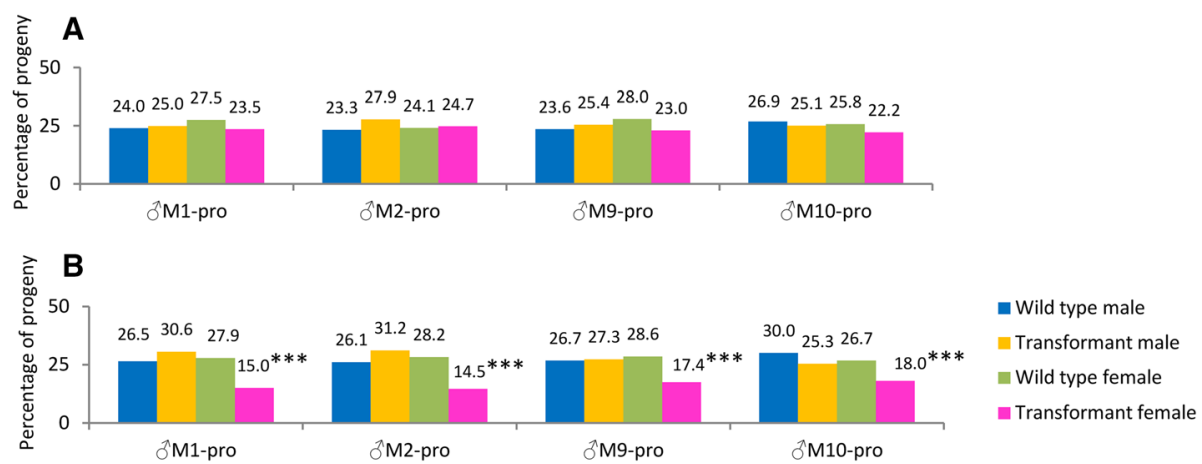

Fig. 3 Segregation ratio of wild-type and heterozygous offspring in crosses between heterozygous male and wild-type mosquitoes at two different hatching times. Hatched eggs were produced from mass crosses between Rock females and heterozygous males ( $\mathrm{O}^{\mathrm{M}} 1$-pro, ${ }^{\top} \mathrm{M} 2$-pro, ${ }^{\top} \mathrm{M} 9$-pro and ${ }^{\top} \mathrm{M} 10-$ pro, the male progenies of M1, M2, M9 and M10). a One thousand eggs from each cross, produced after the first blood meal, showed no significant deviation from the anticipated 1:1:1:1 ratio in all the four mass crosses $(P>0.05 ; d f=3$; all $\left.X^{2} \leq 5.73\right)$. The hatching rates were in the range of $82.2-97.2 \%$. b Two hundred eggs produced as described in A but hatched 1 month later, showed a hatching rate of $74.5-97 \%$ and pooled values of four mass crosses were significantly different from the anticipated 1:1:1:1 ratio due to the mortality of heterozygous females $\left({ }^{* * *} P<0.001\right.$; all $\left.X^{2} \geq 24.20 ; d f=3\right)$. After removing the heterozygous females from the counts, pooled values of heterozygous males, wild-type males and females in B did not deviate significantly from the anticipated 1:1:1 ratio $\left(P>0.05 ; X^{2}=0.00 ; d f=2\right)$. The numbers at the head of each column show the sex ratios of transgenic and wild-type mosquitoes from the same broods. The transgenic mosquitoes used for these crosses varied between 3 and 9 days old. The details of hatching rates and statistical tests are presented in Additional file 5

There was also no female-to-male sex conversion as found in other dipterous insects. Because the knockdown of tra2 does not cause sex conversion even though TRA/TRA-2 regulatory elements are present in female-specific $d s x$ premRNA sequences [29], tra-2 clearly does not play the same role during sex determination in Ae. aegypti as in certain other dipterous insects [18-20].

Interestingly, 200 eggs from the first blood meal batches were hatched a month later and showed a reduction in the proportion of transgenic females (Fig. 3b), resulting in a significant deviation from the anticipated 1:1:1:1 ratio of wild-type males, heterozygous males, wild-type females and heterozygous females $(P<0.001$; $\left.X^{2}=24.20 ; d f=3\right)$. Even in the crosses using the $\$ \mathrm{M} 9$ and ${ }^{1} \mathrm{M} 10$ progeny, in which the sex ratio was unbiased in the first generation (Fig. 2b), the pooled value was significantly distorted in the later-hatching egg batches of the subsequent generation $\left(P<0.05 ; X^{2}=8.99 ; d f=3\right)$ as shown in Fig. 3b.

The differences in sex ratio in the later-hatching egg batches provide convincing evidence against the presence of natural $M D$ drive. The loss of females was confined entirely to the transgenic population $(P<0.001)$, and if these females are excluded there was a 1:1:1 ratio of wild-type males, DsRed-2 males and wild-type females $\left(P>0.05 ; X^{2}=0.00 ; d f=2\right)$ (see Additional file 5). If natural $M D$ drive contaminated or segregated to the insertion in line 6 , it would skew the progeny sex ratio of both the transgenic and wild-type females $[10,11]$. The sequences flanking the insertion in line 6 matched an intergenic region near the Odorant Receptor-84 gene
[AaegL1:supercont1.110], which is unlikely to be an $M D$ enhancer. This supercontig has yet to be mapped onto a chromosome, but the genetic crosses described above confirmed that supercont 1.110 is not a sex-linked region in Ae aegypti chromosome I.

Evidently this sex ratio distortion is caused by the transgene, because even in the absence of $t \mathrm{TA}$, the leaky tet $\mathrm{O}$ sequence $[41,42]$ allowed sufficient residual expression of the tra-2 RNAi construct to inhibit m-chromosomebearing sperm and also $\mathrm{mm}$ zygotes, thus increasing the proportion of male offspring.

\section{Sperm longevity, male age relative to sex ratio distortion and male competence}

The crossing and dissection experiments indicated an association between sperm longevity, sex-specific lethality and transgene expression. To test the consistency of those factors, two homozygous lines ( 2 and 10$)$ were reestablished from the heterozygous progeny of ${ }^{\lambda} \mathrm{M} 2$ and ${ }^{\top} \mathrm{M} 10$ (Fig. 4). ${ }^{1} \mathrm{M} 2$ produced highly-biased male offspring whereas the offspring of $\mathrm{M} 10$ were unbiased. Groups of five 3-day-old and 15-day-old males were collected from lines 2, 10 and Rock, and each male was individually crossed with three virgin Rock females. One of the three was blood fed to lay eggs, the second was dissected to examine the spermathecae immediately after coitus and the third was dissected after 22 days.

In all crosses, the 3-day-old fathers produced normal sperm and 1:1 sex ratios in the offspring (Fig. 4; Additional file 2: Table S4). Active and normal sperm were also found in the spermathecae of the mated females. However, the 


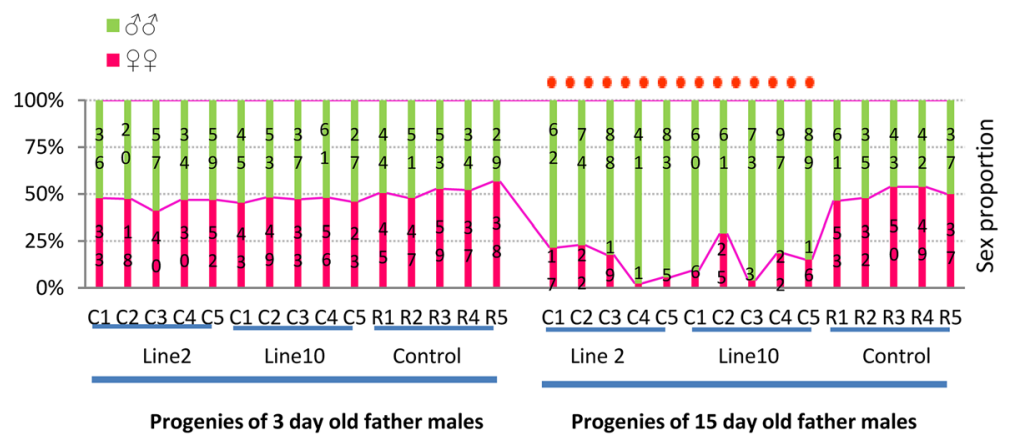

Fig. 4 Transgenic male ages in relation to sex ratio in the next generation. Transgenic homozygous males (C1, C2, C3, C4 and C5) from lines 2 and 10 and control Rock males (R1, R2, R3, R4 and R5) were divided into 3-day-old and 15-day-old age groups. The males in each group were crossed with Rock females. C1-5 and R1-5 are single-pair crosses. The stacked numbers in each column are values observed in each cross. The 3day-old parental males produced no significant deviation from the anticipated 1:1 sex ratio. The red dashed line indicates 10 crosses showing significant deviation from the anticipated 1:1 sex ratio $\left(P<0.001 ; d f=1\right.$; all $\left.X^{2} \geq 15.07\right)$ when parental males were 15 days old. The details of hatching rates and statistical tests are presented in Additional file 5

15-day-old fathers produced a lower density of sperm, and the sex ratios were significantly skewed from 1:1 $(P<0.001$; all $X^{2} \geq 15.1 ; d f=1$ ) (see Additional file 5). The sperm in the spermathecae of females crossed with 15-day-old males were present at a lower density than normal, but dead sperm were not found because these cannot pass into the spermathecae. The presence of sperms that died after entering the spermathecae indicated that the tra-2 knockdown effect may be weak, even in homozygous males. No difference in sperm vitality was observed among the Rock males regardless of age. The spermathecae of females kept for 22 days after mating contained predominantly dead sperm after crossing with lines 2 and 10, whereas living sperm were found in those crossed with Rock males (Fig. 5; Additional file 2: Table S4).

Our results show that tra-2 RNAi causes the haplotypespecific differential depletion of sperm, and that lethality increases with age. The high mortality observed for almost all the sperms in the spermathecae may indicate that the decomposition of dysfunctional $\mathrm{m}$-chromosome-bearing sperm has a toxic effect on those carrying the Mchromosome. Interestingly, the $M D$ effect in Ae. aegypti involved an increase in sperm senescence as well as moderate post-zygotic mortality. In the extreme case, $M D$ affects most sperm, but normal fertility requires no more than $20 \%$ of typical sperm production in Ae. aegypti [10, 43]. In D.simulans, $\mathrm{X}^{\mathrm{K}} \mathrm{s}$ gene not only killed wild-type sperm but many $\mathrm{X}^{\mathrm{K}} \mathrm{s}$ sperm were autolethal $[44,45]$. The mass sperm mortality observed in the Ae. aegypti tra-2 knockdown line may therefore represent an evolutionary strategy similar to natural $M D$, especially given the genetic similarity between the Ae aegypti $\mathrm{m}$-chromosome and M-chromosome. We also tested the mating capacity of transgenic males in competition experiments and found they competed as well as

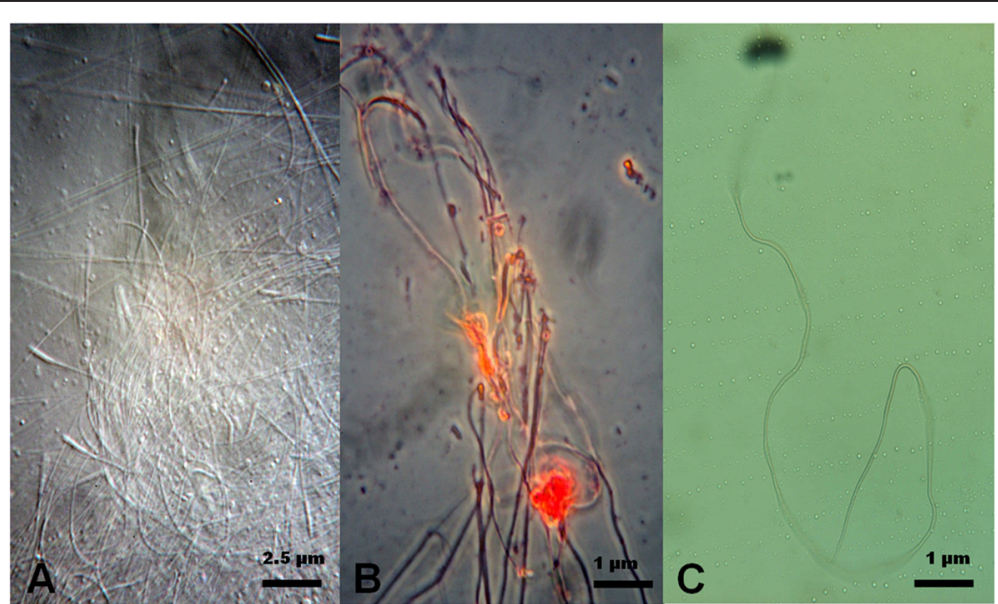

Fig. 5 Dead sperm in the spermathecae of female mosquitoes. a Dead sperm without staining. Scale bar = $2.5 \mu m$. $\mathbf{b}$ Dead sperm stained with Orcein. Scale bar $=1 \mu \mathrm{m}$. c Stained sperm from the age-matched control wild-type males. Scale bar =1 $\mathrm{mm}$. Images captured with a DP50 digital camera fitted to an Olympus BX51 microscope 
wild-type males under cage conditions (Additional file 2: Table S5). We also searched nine insect transcriptomes for $N v d s x R E$ motifs [29] and found that the sequences were prevalent in these species suggesting widespread evolutionary significance (Additional file 2: Table S6).

\section{Microinjection of the tra-2 RNAi construct: transient effect on sex ratios}

The microinjection of tra-2 dsRNA surprisingly produced no effect in Ae. aegypti [27]. To prevent the rapid in vivo degradation of dsRNA, we injected $A e$. aegypti Rock embryos with the tra-2 RNAi plasmid construct at a high concentration of $1.6 \mu \mathrm{g} / \mu \mathrm{l}$. The survivors showed a significant male bias ratio but these males produced a normal sex ratio in subsequent generation, indicating that transient expression of the construct killed female zygotes independent of genetic background or transgene integration effects (Additional file 2: Table S7).

\section{Segregation distortion and Ae. aegypti sex determination} Our results show that Ae.aegypti tra-2 is responsible for a $S D$ mechanism (Fig. 6a and b). Sperms carrying the mchromosome require paternal tra-2 to function correctly, suggesting that tra-2 is potentially a master-control locus for sex-determination which induces the specific

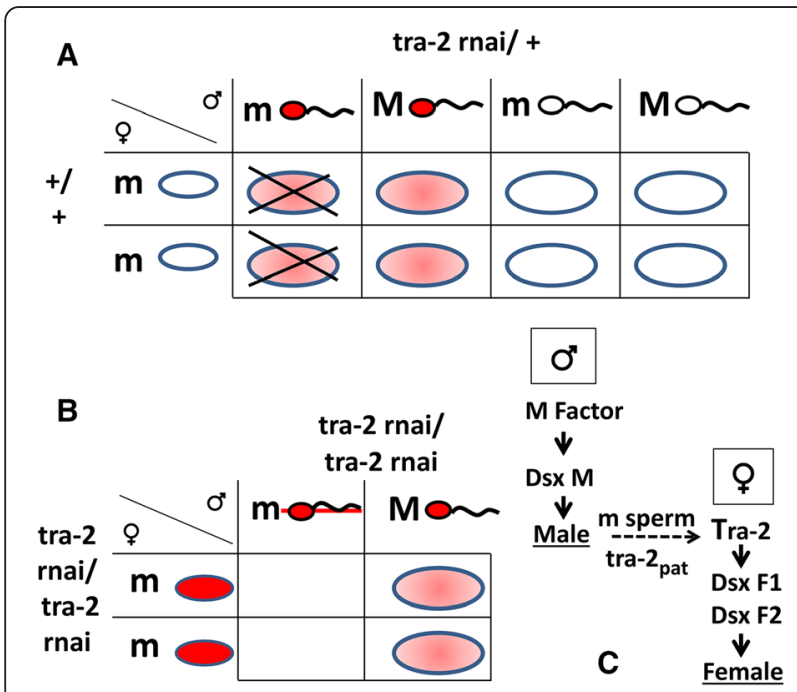

Fig. 6 Female-specific lethality and sex determination. a Punnett square showing tra-2 RNAi segregation in a cross between a heterozygous male and a wild-type female. The knockdown effect driven by the minimal CMV promoter was not enough to cause an obvious effect on sperm activity but specific lethality in $\mathrm{mm}$ zygotes was still evident. b Punnett square showing tra-2 RNAi segregation in a homozygous line, resulting in dysfunctional m-chromosome-bearing sperm during spermatogenesis and no surviving female progeny after fertilization. c Hypothetical model of sex determination in Aedesa egypti in which paternal tra-2 mRNA (tra-2 pat ) is necessary for the activity of m-chromosome-bearing sperms inactivation of sperm carrying the m-chromosome. We propose a model in which the TRA/TRA-2 complex controls the splicing of $d s x$ mRNA, leading to the production of two female-specific isoforms (DSX ${ }^{\mathrm{F} 1}$ and $\mathrm{DSX}^{\mathrm{F} 2}$ ) and the male-specific isoform $\mathrm{DSX}^{\mathrm{M}}$. During zygotic development, $d s x \mathrm{~F} 1$ is not synthesized in the embryo or in the first and second larval stages whereas tra2 knockdown would prevent the synthesis of $d s x \mathrm{~F} 2$ [29]. The $\mathrm{mm}$ genotype is therefore zygotic lethal as found in our experiments (Fig. 6c). The lack of sex conversion indicates that the reversible sex determination of this species is not a maternal decision.

\section{Discussion}

We investigated a transgenic Ae. aegypti line carrying an RNAi construct that specifically targets the tra-2 gene. The analysis of this line in large-scale crosses indicated that the knockdown of tra-2 is probably responsible for the dysfunction of $\mathrm{m}$-chromosome-bearing sperm and female-specific zygotic lethality in the subsequent generation, producing all-male progenies. Although we cannot distinguish dead (m) and living (M) sperm, the mass mortality of sperm and accompanying male bias suggests that tra-2 knockdown causes $S D$. The knockdown of tra-2 in transgenic males did result in the depletion of tra-2 (AAELO04293) mRNA, but quantitative RT-PCR analysis of mRNA from the testes of individual transgenic fathers would provide additional confirmatory data [30]. The homozygous murine $\mathrm{Rb}$ (6.15) Spam1 mutation caused a reduction in mRNA levels (to $45 \%$ of the wild-type level) and heterozygous mice carrying this mutation produced two populations of sperm, one with the mutation being unable to bind to the zona of the egg [46]. In line 6, the tra2 expression level in male homozygotes was reduced by an average of $48.7 \%$ relative to wild-type insects (Standard Deviation $=4.98$ ) [30]. These knockdown levels were not enough to cause sperm dysfunction in heterozygous males, hence the resulting 1:1:1:1 ratio (Additional file 3: Figure S2 and Fig. 3a).

The genetic construct in line 6 behaves oddly because the knockdown occurred even in the absence of $t \mathrm{TA}$ and only some of the crosses showed evidence of $S D$ (Fig. 2a and b). The incomplete penetrance of the $S D$ effect could be caused by the genetic background. However, in ${ }^{\lambda} \mathrm{M} 9$ and ${ }^{\lambda} \mathrm{M} 10$ crosses, the sex ratio was unbiased but the male offspring produced significantly distorted sex ratios if their egg batches were hatched a month later (Fig. 3b). Homozygous 3-dayold males produced 1:1 sex ratios in their offspring but 15-day-old homozygous males consistently produced distorted ratios. The Rock line, which was used to create line 6 , consistently showed a 1:1 sex ratio (Fig. 4). Altogether, these results clearly exclude genetic background effects on the degree of $S D$ and 
indicate that there was a linear relationship between the residual expression of the tra-2 RNAi construct and the age of males.

No sex ratio distortion was found in the progeny of crosses between homozygous females and wild-type Rock males (Fig. 2c) but crosses between homozygous tra-2 RNAi females (Additional file 2: Table S1) [30] and homozygous $L A 513$ males [33] carrying the $t$ TA transactivator gene yielded a significantly biased sex ratio (up to $70 \%$ males) in the absence of tetracycline, indicating that the abnormal sex ratio can be attributed to the fully penetrative activation of the $t \mathrm{TA}$ promoter. These results are consistent with our finding that heterozygous female mortality occurred in the later-hatching egg batches and in the transient expression experiments (Fig. 3b and Additional file 2: Table S7). Altogether, these results indicate that tra-2 RNAi female zygotes can be killed at early stages of development if the knockdown effect is potent, and that the tet transactivator system is suitable for the conditional induction of tra-2 RNAi [31, 47].

Theoretically, an autosomal driver acting on sexchromosomes cannot undergo positive selection because the autosomes would be selected to re-establish an equal sex ratio [48]. Endogenous retrotransposon-dependent RNAi has been shown to cause transmission ratio distortion in D. simulans $[14,15]$ and the multiple tra-2 loci in mosquitoes may have been exploited in a similar manner [49]. The striking similarity between our RNAi phenotype and the natural $M D$ system in terms of sperm depletion/ dysfunction, between-family sex ratio bias, egg hatching rates and zygotic lethality $[10,11,43]$, may indicate the presence of such a genetic element within the $D$ gene and the multiple tra-2 loci may have been selected to counteract the natural $M D$ system [49]. A translocation from chromosome III to the M-chromosome in Ae. aegypti confirms that genetic dominance is not responsible for the $M D$ phenomenon [10]. Our findings strongly support the similarity between tra-2 knockdown and natural $M D$ in Culicine mosquitoes [10-13, 40].

The tra-2 knockdown provides opportunities for the future development of novel vector control strategies. Strongly biased male progeny may encourage the conditional elimination of females, allowing the efficient production of genetic sexing strains that could be used for mosquito control based on SIT [1]. If the tra-2 RNAi construct were linked to the $\mathrm{M}$-chromosome and expressed under a suitable spermatogenesis-specific promoter such as $\beta 2[50,51]$, the dsRNA could be used to target all $\mathrm{m}$-chromosome-bearing sperm $[52,53]$ and rapidly masculinize a target population $[54,55]$. This is not a purely speculative proposal because 15-day-old homozygous males produced all biased offspring but heterozygous males produced offspring with normal Mendelian segregation, suggesting that a powerful spermatogenesis-specific promoter may cause $S D$ in the offspring with $100 \%$ penetrance whether the father is homozygous or heterozygous. A suppressor RNAi construct that can inhibit $t \mathrm{TA}$ gene expression in the $\mathrm{M}$ linked tra-2 RNAi construct could also be used as a vehicle to carry new genes into a population [56].

A recent article [57] has reported that feeding mosquito larvae with dsRNAs targeting testis-specific genes produces adult males with greatly reduced fertility. RNAi-mediated knockdown of the female-specific isoform of $d s x$ also induces female lethality and a highly-male-biased population of mosquitoes. This $d s x$ knockdown-dependent female lethality is consistent with our observed female-specific zygotic lethality, given the interaction between $d s x$ and tra-2, and this finding could revolutionize the SIT method. For example, Glossina spp. (tsetse flies) are viviparous, preventing the application of conventional transgenic methods, but dsRNAs feeding may allow the application of SIT [58].

If mosquito larvae are fed tra-2 dsRNA, a male-biased population would be anticipated with few females surviving until adulthood. The advantage of a conditionallytransgenic tra-2 RNAi system is that specific promoters could be used to restrict the fatal effect of tra-2 RNAi solely to the $\mathrm{m}$-sperm, leaving the females intact. Eggs produced by such transgenic lines should give rise to males only, which could be stored in a conventional manner and delivered when necessary within a few months, thus avoiding the need to rear millions of male insects per week. The first major success of a mosquito SIT program was achieved against $C x$. pipiens fatigans in Myanmar [59], in which SIT males sterilized wild female counterparts by carrying different strains of Wolbachia to those carrying by the natural mosquito populations. This can be applied to minimize concerns coupled with the release of transgenic organisms, the sterility of the released males would ensure biological containment and prevent the spread of transgenes. If a transgenic Ae. aegypti line carrying wMel Wolbachia was allowed to mate wild females, no offspring would be produced due to their complete cytoplasmic incompatibility $[60,61]$.

\section{Conclusion}

We have investigated the function of the tra-2 gene in an Ae.aegypti tra-2 RNAi transgenic line. We found that the knockdown of tra-2 gene expression causes a bias in the sex ratio of the next generation due to segregation distortion acting at the level of gametic function and female-specific zygotic lethality. All 15-day-old homozygous fathers produced significantly male biased progeny, which indicates similar penetration of the genetic construct in age-matched males and that the tra-2 RNAi construct could be used as a sex distorter system. A fully conditional tet regulatory system would be needed to 
establish Ae. aegypti genetic sexing strains that could be integrated into control techniques based on SIT or RIDL.

\section{Availability of supporting data}

The data sets supporting the results in this article are included within the article and its additional files.

\section{Additional files}

Additional file 1: Figure S1. Construct schematic. Schematic representation of the Zoo-2 vector [30], linearized at the $3^{\prime}$ end of the PiggyBac transposon. The inserted sequences enhance the efficiency of intron splicing. The two functional segments include the marker (Act5C promoter, DsRed-2, Drosomycin 3'-UTR) and a tra-2 RNAi cassette (tetO7-CMV minimal promoter, RRM inverted repeats joined by the tra- 2 intron and rabbit $\beta$-globulin 3 '-UTR). (TIF $1813 \mathrm{~kb}$ )

Additional file 2: Supporting Information in Tables. (DOCX 38 kb)

Additional file 3: Figure S2. The expression of tra-2 in wild-type males and tra-2 RNAi transgenic males. Quantitative real-time PCR was also used to detect the level of tra-2 mRNA remaining in homozygous male pupae of line 6 (red) and wild-type Rock male pupae (blue). The tra-2 expression level was reduced by an average of $48.7 \%$ in line 6 relative to wild-type insects in three replicates (Standard Deviation $=4.98$ ) [30]. (TIF $8549 \mathrm{~kb}$ )

Additional file 4: Figure S3. Schematic representation of the homologous TRA-2 proteins. (A) Protein encoded by the AAEL009224 gene located on supercontig 1.381. (B) Protein encoded by the AAEL009222 gene located on supercontig 1.381. (C) Protein encoded by the AAEL006416 gene located on supercontig 1.204. (D) Protein encoded by the AAEL004293 gene located on supercontig 1.113. These proteins were annotated by merging Ensembl and TIGR prediction sets in Vector Base: Aedes aegypti. (E) RNAi target site in the RRM region of the AAEL004293 gene. (TIFF $5036 \mathrm{~kb}$ )

Additional file 5: The accession numbers of the RRM sequences: [GenBank: KJ147314, KJ147315, KJ147316, KJ147317, KJ147318, KJ147319, KJ147320, KJ147321]. (XLSX 26 kb)

\section{Competing interests}

We declare the following interests: A PCT patent application about the creation of an all-male population of Culicinae mosquitoes was filed (PCT/ VN2011/000011). Dr. Tze Min Teo (TMT) is currently employed by Advance Agriecological Research Sdn. Bhd, which provided support in the form of a salary for this author. Advance Agriecological Research Sdn. Bhd did not have any additional role in the study design, data collection and analysis, decision to publish, or preparation of the manuscript. The specific role of this author is articulated in the 'author contributions' section. This work was financially supported by the QKHCN.13.01 project, Vietnam National University Hanoi; Vina-UK Business Ltd; and a private sponsor, Dr Thanh Duong Hoang. The funders had no role in study design, data collection and analysis, decision to publish, or preparation of the manuscript. VinaUK Business Ltd has no competing interests in relation to this work. All the authors declare no competing interests.

\section{Authors' contributions}

$\mathrm{KPH}$ designed the experiments and performed inverse PCR, crosses for genetic analysis and meiotic drive testing, microinjections, dissections, artificial mating experiments, and statistical data analysis. TMT performed the phylogenetic analysis for RRM homologs. TXH sequenced the RRMs. KPH and VSL performed statistical data analysis and searches for the specific splicing motifs in nine taxa. KPH wrote the paper. All authors read and approved the final manuscript.

\section{Acknowledgements}

We would like to thank R. J. Wood for the analysis and interpretation of the meiotic drive phenotype and for his advice to determine the survival of heterozygote T37 sperms in spermathecae. We thank H. Townson, R. J. Wood and R. M. Twyman for manuscript editing. We thank H. Townson, P. A. Papathanos, R. Lees and Z. Kambris for valuable comments. We thank Q. S. Le and H. Q. Vu for advice on statistical analysis. We thank N. C. Nguyen for providing facilities at IEBR-VAST, Vietnam. We thank P. Reiter and A. Mercier for providing the Pasteur Institute Rock line, S. Pinto for providing the Oxford Rock line, A. Lynch for providing the LSTM Rock line, and D. Severson for providing the T37 and RED lines. We thank W. Matten for providing the transcript database. We thank B. H. Nguyen, T. V. Tran, T. D. Hoang, D. M. Nguyen, L. D. Hoang and N. Swami for collecting Ae. albopictus and Ae. polynesiensis samples. We thank D. T. Nguyen, H. V. Nguyen, for their help with the fieldwork.

Dr. Tze Min Teo is currently employed by Advance Agriecological Research Sdn. Bhd. Advance Agriecological Research Sdn. Bhd provided support in the form of salary for author TMT, but did not have any additional role in the study design, data collection and analysis, decision to publish, or preparation of the manuscript. This work was financially supported by the QKHCN.13.01 project, Vietnam National University Hanoi; Vina-UK Business Ltd; and a private sponsor, Dr Thanh Duong Hoang. The funding from the QKHCN.13.01 project was used for data analysis and bioinformatics. The funding from Vina-UK Business Ltd and Dr Thanh Duong Hoang was used for experiments, travelling costs, sample collection and editing the manuscript. The funders had no role in study design, data collection and analysis, decision to publish, or preparation of the manuscript. Vina-UK Business Ltd has no any competing interests in relation to this work.

\section{Author details}

'University of Engineering and Technology, Vietnam National University, Hanoi, 144 Xuan Thuy, Cau Giay 10000Hanoi, Vietnam. ${ }^{2}$ Advanced Agriecological Research Sdn. Bhd, No. 11 Jalan Teknologi 3/6, 47810 Petaling Jaya, Selangor, Malaysia. ${ }^{3}$ Department of Plant Pathology, University of Arkansas, 495 N Campus Drive, Fayetteville, AR 72701, USA.

Received: 21 September 2015 Accepted: 20 January 2016 Published online: 28 January 2016

References

1. Knipling E. Possibilities of insect control or eradication through use of sexually sterile males. J Econ Entomol. 1955;48:459-62.

2. Thomas DD, Donnelly CA, Wood RJ, Alphey LS. Insect population control using a dominant, repressible, lethal genetic system. Science. 2000; 287(5462):2474-6.

3. Benedict MQ, Robinson AS. The first releases of transgenic mosquitoes: an argument for the sterile insect technique. Trends Parasitol. 2003; 19(8):349-55

4. Winskill P, Harris AF, Morgan SA, Stevenson J, Raduan N, Alphey L, et al. Genetic control of Aedes aegypti: data-driven modelling to assess the effect of releasing different life stages and the potential for long-term suppression. Parasites Vectors. 2014:7:68. doi:10.1186/1756-3305-7-68.

5. Hamady D, Ruslan NB, Ahmad AH, Rawi CS, Ahmad H, Satho T, et al. Colonized Aedes albopictus and its sexual performance in the wild: implications for SIT technology and containment. Parasites Vectors. 2013;6:206.

6. Ansari M, Singh K, Brooks G, Malhotra P, Vaidyanathan V. The development of procedures and techniques for mass rearing of Aedes aegypti. Indian J Med Res. 1977;65(Suppl):91-9.

7. Fu G, Lees RS, Nimmo D, Aw D, Jin L, Gray P, et al. Female-specific flightless phenotype for mosquito control. Proc Natl Acad Sci U S A. 2010;107:4550-4.

8. Bargielowski I, Kaufmann C, Alphey L, Reiter P, Koella J. Flight performance and teneral energy reserves of two genetically-modified and one wild-type strain of the yellow fever mosquito Aedes aegypti. Vector Borne Zoonotic Diseases. 2012;12:1053-8.

9. U'beda F, Patten MM, Wild G. On the origin of sex chromosomes from meiotic drive. Proc R Soc B. 2015;282:20141932. http://dx.doi.org/10. 1098/rspb.2014.1932.

10. Wood RJ, Newton ME. Sex-ratio distortion caused by meiotic drive in mosquitoes. Am Nat. 1991;137:379-91.

11. Hickey WA, Craig GB Jr. Genetic distortion of sex ratio in a mosquito, Aedes aegypti. Genetics. 1966a; 53: 1177-96.

12. Youngson JHAM, Welch HM, Wood RJ. Meiotic drive at the $D(M D)$ locus and fertility in the mosquito, Aedes aegypti (L.). Genetica. 1981;54:335-40. 
13. Mori A, Chadee DD, Graham DH, Severson DW. Reinvestigation of an endogenous meiotic drive system in the mosquito, Aedes aegypti (Diptera: Culicidae). J Med Entomol. 2004;41(6):1027-33.

14. Tao Y, Masly JP, Araripe L, Ke Y, Hartl DL. A sex-ratio system in Drosophila simulans. I: An autosomal suppressor. PLoS Biol. 2007. doi:10.1371/journal. pbio.0050292

15. Tao Y, Araripe L, Kingan SB, Ke Y, Xiao H, Hartl DL. A sex-ratio meiotic drive system in Drosophila simulans. II: An X-linked distorter. PLoS Biol. 2007:5:e293.

16. Hall AB, Basu S, Jiang X, Qi Y, Timoshevskiy VA, Biedler JK, et al. A maledetermining factor in the mosquito Aedes aegypti. Science. 2015;348(6240): 1268-70. DOI:10.1126/science.aaa2850.

17. Hoshijima KK, Inoue I, Higuchi HS, Shimura Y. Control of doublesex alternative splicing by transformer and transformer-2 in Drosophila. Science. 1991;252:833-6.

18. Fortier E, Belote JM. Temperature-dependent gene silencing by an expressed inverted repeat in Drosophila. Genesis. 2000;26(4):240-4.

19. Sarno F, Ruiz MF, Ecrin-Lopez JM, Perondini AL, Selivon D, Sánchez L. The gene transformer-2 of Anastrepha fruit flies (Diptera, Tephritidae) and its evolution in insects. BMC Evol Biol. 2010. doi:10.1186/1471-2148-10-140.

20. Salvemini M, Robertson M, Aronson B, Atkinson P, Polito LC, Saccone G. Ceratitis capitata transformer-2 gene is required to establish and maintain the autoregulation of Cctra, the master gene for female sex determination. Int J Dev Biol. 2009:53:109-20.

21. Taylor BJ, Knittel LM. Sex-specific differentiation of a male specific abdominal muscle, the muscle of Lawrence, is abnormal in hydroxyu reatreated and in fruitless male flies. Development. 1995;121:3079-88.

22. Taylor BJ, Villella A, Ryner LC, Baker BS, Hall JC. Behavioral and neurobiological implications of sex-determining factors in Drosophila. Dev Genet. 1994;15:275-96

23. Mattox W, Palmer MJ, Baker BS. Alternative splicing of the sex determination gene transformer-2 is sex-specific in the germ line but not in the soma. Genes Dev. 1990:4:789-805.

24. Belote JM, Baker BS. The dual functions of a sex determination gene in Drosophila melanogaster. Dev Biol. 1983;95:512-7.

25. Amrein $H$, Maniatis T, Nothiger R. Alternatively spliced transcripts of the sex-determining gene tra-2 of Drosophila encode functional proteins of different size. EMBO J. 1990;9:3619-29.

26. White-Cooper H. Molecular mechanisms of gene regulation during Drosophila spermatogenesis. Reproduction. 2010;139:11-21.

27. Salvemini M, D'Amato R, Petrella V, Aceto S, Nimmo D, Neira M, et al. The orthologue of the fruitfly sex behaviour gene fruitless in the mosquito Aedes aegypti: Evolution of genomic organisation and alternative splicing. PLoS One. 2013. doi:10.1371/journal.pone.0048554.

28. Birney E, Kumar S, Krainer AR. Analysis of the RNA-recognition motif and RS and RGG domains: Conservation in metazoan pre-mRNA splicing factors. Nucleic Acids Res. 1993;21:5803-16.

29. Salvemini M, Mauro U, Lombardo F, Milano A, Zazzaro V, Arcà B, et al. Genomic organization and splicing evolution of the doublesex gene, a Drosophila regulator of sexual differentiation, in the dengue and yellow fever mosquito Aedes aegypti. BMC Evol Biol. 2011;11:41. http://www. biomedcentral.com/1471-2148/11/41.

30. Teo TM: Sex Determination and Sex Ratio Distortion in the Mosquito Aedes aegypti. Dphil thesis. University of Oxford: UK. http://ora.ox.ac.uk/objects/ uuid:4e2bcfe2-7921-421a-9a01-e5c3c41ecdc6 (2010). Accessed 12 Nov 2014

31. Gossen M, Bujard $\mathrm{H}$. Tight control of gene expression in mammalian cells by tetracycline-responsive promoters. Proc Natl Acad Sci U S A. 1992;89(12):5547-51.

32. Bello B, Resendez-Perez D, Gehring WJ. Spatial and temporal targeting of gene expression in Drosophila by means of a tetracycline-dependent transactivator system. Development. 1998;125:2193-202.

33. Hoang KP, Andreasen MH, Burton RS, Vass C, Epton MJ, Pape G, et al. Lateacting dominant lethal genetic systems and mosquito control. BMC Biol. 2007:5:1-11

34. Tamura K. MEGA5: molecular evolutionary genetics analysis using maximum likelihood, evolutionary distance, and maximum parsimony methods. Mol Biol Evol. 2011;28(10):2731-9.

35. Nei M, Kumar S. Molecular Evolution and Phylogenetics. Oxford: Oxford University Press; 2000. p. 75-229.

36. Munstermann LE. The Molecular Biology of Insect Vectors of Disease, eds. Crampton, J. M., Beard, C. B. \& Louis, C. Chapman \& Hall, London; 1997. p. 13-20.
37. Handler AM, McCombs SD, Fraser MJ, Saul SH. The lepidopteran transposon vector, piggyBac, mediates germ-line transformation in the Mediterranean fruit fly. Proc Natl Acad Sci U S A. 1998;95(13):7520-5.

38. Ow Yang CK, Sta FLM, Wharton RH. Maintenance of laboratory colony of Anopheles maculatus Theobald by artificial mating. Mosq.News. 1963;23:34-35.

39. Scali C, Catteruccia F, Li Q, Crisanti A. Identification of sex-specific transcripts of the Anopheles gambiae doublesex gene. J Exp Biol. 2005;208:3701-9.

40. Sweeny $T L$, Barr AR. Sex ratio distortion caused by meiotic drive in a mosquito, Culex pipiens L. Genetics. 1978:88:427-46.

41. Cavalli G, Paro R. Epigenetic inheritance of active chromatin after removal of the main transactivator. Science. 1999;286:955-8.

42. Yagi R, Mayer F, Basler K. Refined LexA transactivators and their use in combination with the Drosophila Gal4 system. Proc. Natl. Acad. Sci. U.S.A. 2010;107(37):16166-71

43. Owusu-Daaku KO, Butler RD, Wood RJ. Meiotic drive by the Y-linked D gene in Aedes aegypti (L.) (Diptera: Culicidae) is associated with disruption of spermiogenesis, leading to premature senescence of spermatozoa. Arthropod Struct Dev. 2007;36(2):233-43.

44. Montchamp-Moreau C, Joly D. Abnormal spermiogenesis is associated with the X-linked sex-ratio trait in Drosophila simulans. Heredity. 1997;79:24-30.

45. Cazemajor M, Joly D, Montchamp-Moreau C. Sex-ratio drive in Drosophila simulans is related to equational non-disjunction of the $Y$ chromosome. Genetics. 2000;154:229-36.

46. Zheng Y, Deng X, Martin-DeLeon PA. Lack of sharing of Spam 1(Ph-20) among mouse spermatids and transmission ratio distortion. Biol Reprod. 2001:64:1730-8

47. Gossen M, Freundlieb S, Bender G, Muller G, Hillen W, Bujard H. Transcriptional activation by tetracycline in mammalian cells. Science. 1995;268(5218):1766-9.

48. Hamilton WD. Extraordinary sex ratios. A sex-ratio theory for sex linkage and inbreeding has new implications in cytogenetics and entomology. Science. 1967;156:477-88. doi:10.1371/journal.pbio.0050293.

49. Liu P, Chen Y, Gu J, Chen X. Isolation and expression profiling of transformer 2 gene in Aedes aegypti. J South Med Univ. 2013;33(11):1583-9.

50. Catteruccia F, Benton JP, Crisanti A. An Anopheles transgenic sexing strain for vector control. Nature Biotechnol. 2005;23:1414-7.

51. White-Cooper H. Tissue, cell type and stage-specific ectopic gene expression and RNAi induction in the Drosophila testis. Spermatogenesis. 2012;2(1):11-22.

52. Windbichler N, Papathanos PA, Crisanti A. Targeting the X chromosome during spermatogenesis induces $Y$ chromosome transmission ratio distortion and early dominant embryo lethality in Anopheles gambiae. PLoS Genet. 2008. doi:10.1371/journal.pgen.1000291.

53. Braun RE, Behringer RR, Peschon JJ, Brinster RL, Palmiter RD. Genetically haploid spermatids are phenotypically diploid. Nature. 1989;337(6205):373-6.

54. Huang Y, Magori K, Lloyd AL, Gould F. Introducing desirable transgenes into insect populations using $Y$-linked Meiotic Drive-A theoretical assessment. Evolution. 2007:61(4):717-26.

55. Wood RJ, Ouda NA. The genetic basis of resistance and sensitivity to the meiotic drive gene $D$ in the mosquito Aedes aegypti L. Genetica. 1987:72:69-79.

56. James A, Benedict M, Christophides G, Jacobs-Lorena M, Olson K. Evaluation of drive mechanisms (including transgenes and drivers) in different environmental conditions and genetic backgrounds. In: Knols, BGJ. Louis, C., editors. Bridging Laboratory and Field Research for Genetic Control of Disease Vectors. Netherlands: Springer; 2006.p.149-155.

57. Whyard S, Erdelyan CNG, Partridge AL, Singh AD, Beebe NW, Capina R. Silencing the buzz: A new approach to population suppression of mosquitoes by feeding larvae double-stranded RNAs. Parasites Vectors. 2015:81: doi:10.1186/s13071-015-0716-6

58. Marquardt WC. The Biology of Disease vectors, eds. Beaty BJ, Marquardt WC. P. O. Box 849. Niwot, Colorado 80544: University Press of Colorado; 1996.p.128-45.

59. Laven $\mathrm{H}$. Eradication of Culex pipiens fatigans through cytoplasmic incompatibility. Nature. 1967;216:383-4.

60. Hoffmann AA, Iturbe-Ormaetxe I, Callahan AG, Phillips BL, Billington K, Axford JK, et al. Stability of the WMel Wolbachia infection following invasion into Aedes aegypti populations. PLoS Negl Trop Dis. 2014;8:e3115. doi:10. 1371/journal.pntd.000311525211492.

61. Segoli M, Hoffmann AA, Lloyd J, Omodei GJ, Ritchie SA. . The Effect of Virus-Blocking Wolbachia on Male Competitiveness of the Dengue Vector Mosquito, Aedes aegypti. PLoS Negl Trop Dis. 2014;8(12):e3294. doi:10.1371/journal.pntd.0003294. 